\title{
Erratum to: High-Ti, bright-CL rims in volcanic quartz: a result of very rapid growth
}

\author{
Ayla S. Pamukcu ${ }^{1,2}$ - Mark S. Ghiorso ${ }^{3}$ Guilherme A. R. Gualda ${ }^{4}$
}

Published online: 12 January 2017

(C) Springer-Verlag Berlin Heidelberg 2017

\section{Erratum to: Contrib Mineral Petrol (2016) 171:105 DOI 10.1007/s00410-016-1317-x}

Some errors were introduced in Table 1 during production of the original version of this manuscript. Below is the correct version of the table (Table 1).
Table 1 Model input values

\begin{tabular}{lll}
\hline & $\mathrm{Ti}$ & $\mathrm{CO}_{2}$ \\
\hline$K_{\mathrm{i}}$ & 0.104 & 0.001 \\
& Anderson et al. (2000) & Baker et al. (2005) \\
$D_{\mathrm{i}}$ & $9.05 \times 10^{-13} \mathrm{~m}^{2} / \mathrm{s}$ & $2.0 \times 10^{-11} \mathrm{~m}^{2} / \mathrm{s}$ \\
& Hayden and Watson (2006) & Watson $(1991)$ \\
& & $2.4 \times 10^{-12} \mathrm{~m}^{2} / \mathrm{s}$ \\
& & Fogel and Rutherford (1990) \\
$V(t)$ & $10^{-7}-10^{-13} \mathrm{~m} / \mathrm{s}$ & $10^{-7}-10^{-13} \mathrm{~m} / \mathrm{s}$ \\
& Pamukcu et al. (2015) & Pamukcu et al. (2015) \\
& Seitz et al. (2016) & Seitz et al. (2016) \\
& Gualda (in prep) & Gualda (in prep) \\
& Minute-year & Minute-year \\
& Pamukcu et al. (2015) & Pamukcu et al. (2015) \\
& Gualda (in prep) & Gualda (in prep) \\
$C_{\mathrm{o}}$ & 0.5 & 0.5 \\
\hline
\end{tabular}

The online version of the original article can be found under doi:10.1007/s00410-016-1317-x.

Ayla S. Pamukcu

ayla@princeton.edu

1 Department of Geosciences, Princeton University, Princeton, NJ 08544, USA

2 Department of Earth, Environmental and Planetary Sciences, Brown University, Providence, RI 02912, USA

3 OFM Research, 7336 24th Ave NE, Seattle, WA 98115, USA

4 Department of Earth and Environmental Sciences, Vanderbilt University, Nashville, TN 37235, USA 